\title{
Demonstration of 4Gbit/s Duobinary Ka-Band Hybrid Photonic-Wireless Transmission
}

Rommel, Simon; Yi, Lilin; Shi, Mengyue; Tafur Monroy, Idelfonso ; Vegas Olmos, Juan José

Publication date:

2015

Document Version

Publisher's PDF, also known as Version of record

Link back to DTU Orbit

Citation (APA):

Rommel, S., Yi, L., Shi, M., Tafur Monroy, I., \& Vegas Olmos, J. J. (2015). Demonstration of 4Gbit/s Duobinary Ka-Band Hybrid Photonic-Wireless Transmission. Paper presented at Asia Communications and Photonics Conference 2015, Hong Kong, Hong Kong.

\section{General rights}

Copyright and moral rights for the publications made accessible in the public portal are retained by the authors and/or other copyright owners and it is a condition of accessing publications that users recognise and abide by the legal requirements associated with these rights.

- Users may download and print one copy of any publication from the public portal for the purpose of private study or research.

- You may not further distribute the material or use it for any profit-making activity or commercial gain

- You may freely distribute the URL identifying the publication in the public portal

If you believe that this document breaches copyright please contact us providing details, and we will remove access to the work immediately and investigate your claim 


\title{
Demonstration of 4Gbit/s Duobinary Ka-Band Hybrid Photonic-Wireless Transmission
}

\author{
Simon Rommel ${ }^{1}$, Lilin $\mathrm{Yi}^{2}$, Mengyue $\mathrm{Shi}^{2}$, Idelfonso Tafur Monroy ${ }^{1}$, J. J. Vegas Olmos ${ }^{1}$ \\ ${ }^{I}$ Department of Photonics Engineering, Technical University of Denmark, 2800 Kgs. Lyngby, Denmark \\ ${ }^{2}$ State Key Laboratory of Advanced Optical Communication Systems and Networks, Shanghai Jiao Tong University, \\ Shanghai 200240, China \\ sirem@fotonik.dtu.dk
}

\begin{abstract}
We demonstrate transmission of a 4Gbit/s duobinary signal over a Ka-band hybrid photonic-wireless link consisting of $12.5 \mathrm{~km}$ SMF and $2 \mathrm{~m}$ wireless distance, using RF carrier frequencies aligned with the Ka-band spectrum allocations for mobile communications. OCIS codes: (060.5625) Radio frequency photonics; (060.4510) Optical communications.
\end{abstract}

\section{Introduction}

The ever increasing demand for high-speed mobile data services and resulting need for larger bandwidth channels have brought millimeter wave $(\mathrm{mmw})$ carrier frequencies into the focus for future wireless communications [1-3]. In the IEEE Ka-band, i.e. the frequency range between $26.5 \mathrm{GHz}$ and $40 \mathrm{GHz}$ and thus the lower edge of the mmw range, two bands around $28 \mathrm{GHz}$ and $36 \mathrm{GHz}$ have been allocated for possible use in mobile communication networks with an additional allocation in the adjacent $\mathrm{K}$-band at $24 \mathrm{GHz}$. These bands have attracted considerable interest [1,2] and channel characterizations have found them suitable for both indoor and outdoor communications [1].

Although these bands allow for larger channel bandwidths the efficient use thereof remains an important issue and a trade-off between spectral efficiency and the complexity of transmitting and receiving equipment must be found. Duobinary signaling has been shown to allow doubling the spectral efficiency compared to on-off keying [4-6] while maintaining receiver simplicity.

In this paper we demonstrate transmission of a $4 \mathrm{Gbit} / \mathrm{s}$ duobinary signal over a Ka-band hybrid photonic-wireless link, including fiber transmission over $12.5 \mathrm{~km}$ and wireless distances up to $2 \mathrm{~m}$.

\section{Duobinary Signaling}

Polybinary or partial response signaling has been proposed to reduce the spectral occupation of a signal by introducing correlation between adjacent transmission symbols [4-6]. In the case where a polybinary sequence is generated digitally rather than through strong filtering of an NRZ signal [7] this correlation is introduced by transmitting an $M$-level sequence $\left\{c_{k}\right\}$ where each symbol is the algebraic sum of the current and $M-2$ preceding bits of the sequence $\left\{b_{k}\right\}$ :

$$
c_{k}=\sum_{i=0}^{M-2} b_{k-i}
$$

If the elements of the latter are obtained from an input bit sequence $\left\{a_{k}\right\}$ and $M-2$ of its own previous elements according to the precoding relationship

$$
b_{k}=a_{k} \oplus b_{k-1} \oplus b_{k-2} \oplus \ldots \oplus b_{k-M+2}
$$

(where $\oplus$ represents the exclusive-or binary logic), then at the receiver an estimate $\left\{\hat{a}_{k}\right\}$ of the sequence $\left\{a_{k}\right\}$ can be recovered element-wise by a simple symbol-by-symbol detector performing the modulo 2 operation on the value of the elements of the received sequence $\left\{\hat{c}_{k}\right\}$

$$
\hat{a}_{k}=\hat{c}_{k} \bmod 2
$$

preventing error propagation which would affect uncoded polybinary signaling [5].

For duobinary signaling - the simplest case of polybinary signaling with $M=3$-this allows a reduction of spectral occupation by a factor of two as shown in Fig. 1, comparing the bandwidth of $4 \mathrm{Gbit} / \mathrm{s}$ NRZ and duobinary signals generated with an arbitrary waveform generator. The observed $3 \mathrm{~dB}$ bandwidths of $1.5 \mathrm{GHz}$ and $0.75 \mathrm{GHz}$ and $10 \mathrm{~dB}$ bandwidths of $2.8 \mathrm{GHz}$ and $1.4 \mathrm{GHz}$ respectively further show the $10 \mathrm{~dB}$ bandwidth of the duobinary signal to be below the $3 \mathrm{~dB}$ bandwidth of the NRZ signal of the same data rate. 


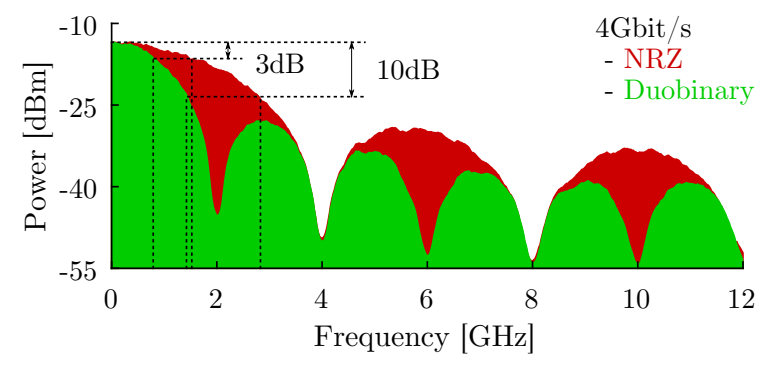

Fig. 1. Comparison of the bandwidth requirements for $4 \mathrm{Gbit} / \mathrm{s} \mathrm{NRZ}$ and duobinary signals obtained from an arbitrary waveform generator

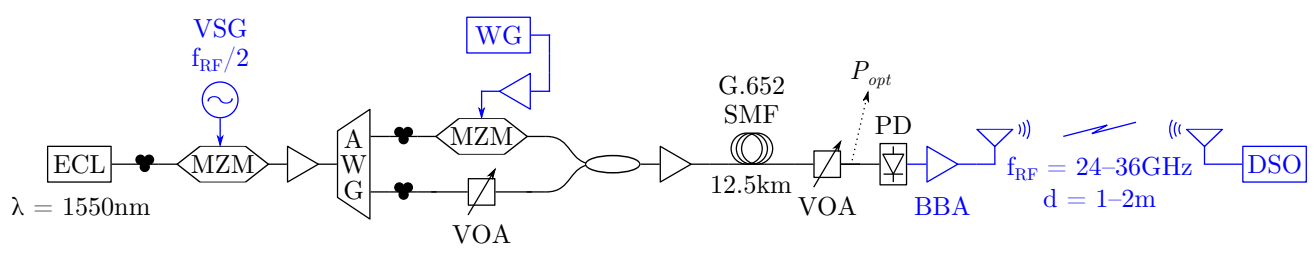

Fig. 2. Experimental setup for Ka-band hybrid photonic-wireless transmission. ECL: external cavity laser, VSG: vector signal generator, MZM: Mach-Zehnder modulator, AWG: arrayed waveguide grating, WG: arbitrary waveform generator, VOA: variable optical attenuator, SMF: single-mode fiber, PD: photodiode, BBA: RF broadband amplifier, DSO: digital storage oscilloscope

\section{Experimental Setup}

The Ka-band transmission setup is depicted in Fig. 2. Photonic up-conversion is employed at the transmitter, consisting of an external cavity laser (ECL) at $\lambda=1550 \mathrm{~nm}$, followed by a Mach-Zehnder modulator (MZM) driven with a sinusoidal at $f_{R F} / 2$ to generate two spectral lines spaced at $f_{R F}$. While the wavelength of the ECL is constant, the driving frequency for the MZM is varied in order to generate line spacings between $24 \mathrm{GHz}$ and $36 \mathrm{GHz}$.

The signal is amplified and an arrayed waveguide grating (AWG) separates the two lines while suppressing the residual carrier, allowing one line to be modulated with a $4 \mathrm{Gbit} / \mathrm{s}$ duobinary signal in a second MZM driven by the amplified output of an arbitrary waveform generator (WG). The duobinary signal is generated offline by precoding a $2^{15}-1$ bit long pseudo-random bit sequence (PRBS15) according to (2) and duobinary signal generation as in (1); it is upsampled to $12 \mathrm{GSa} / \mathrm{s}$ and uploaded to the output memory of the WG. The two signal lines are recombined, amplified and transmitted through $12.5 \mathrm{~km}$ of ITU-T G.652 standard single-mode fiber (SMF).

At the transmit antenna a variable optical attenuator (VOA) allows variation of the optical power $P_{\text {opt }}$ incident on the photodiode (PD) between $0 \mathrm{dBm}$ and $8 \mathrm{dBm}$, thus affording control over the power of the output RF signal at $f_{R F}$ resulting from the beating of the two signal lines on the PD. The RF signal is amplified with a broadband RF amplifier (BBA) with a nominal gain and $3 \mathrm{~dB}$ bandwidth of $29 \mathrm{~dB}$ and $38 \mathrm{GHz}$ respectively. A pair of Ka-band pyramidal horn antennas — with a gain of $20 \mathrm{dBi}$ each —allows wireless transmission of the RF signal.

The received signal is directly recorded using a digital storage oscilloscope (DSO) and digitally bandfiltered, downconverted and low-pass filtered in offline signal processing. Finally bit-error rate (BER) values are determined through symbol-by-symbol detection as per (3) and error counting over multiple recorded sequences with a combined length $>1$ Mbit.

\section{Experimental Results}

We demonstrate transmission of a $4 \mathrm{Gbit} / \mathrm{s}$ duobinary signal over a hybrid photonic-wireless link using RF carrier frequencies in the Ka-band. Transmission performance is analyzed as a function of optical power $P_{\text {opt }}$ incident on the PD and for carrier frequencies representative of the frequency bands allocated to mobile transmissions in the Ka-band.

Fig. 3 shows obtained BER values for transmission over $12.5 \mathrm{~km}$ of SMF and wireless distances of $1 \mathrm{~m}$ and $2 \mathrm{~m}$, using RF carriers at $24 \mathrm{GHz}, 28 \mathrm{GHz}$ and $36 \mathrm{GHz}$. In all cases transmission performance increases with increasing power on the PD—and thus increasing RF power — up to an optimum of about $P_{\text {opt }}=5 \mathrm{dBm}$, beyond which performance begins 


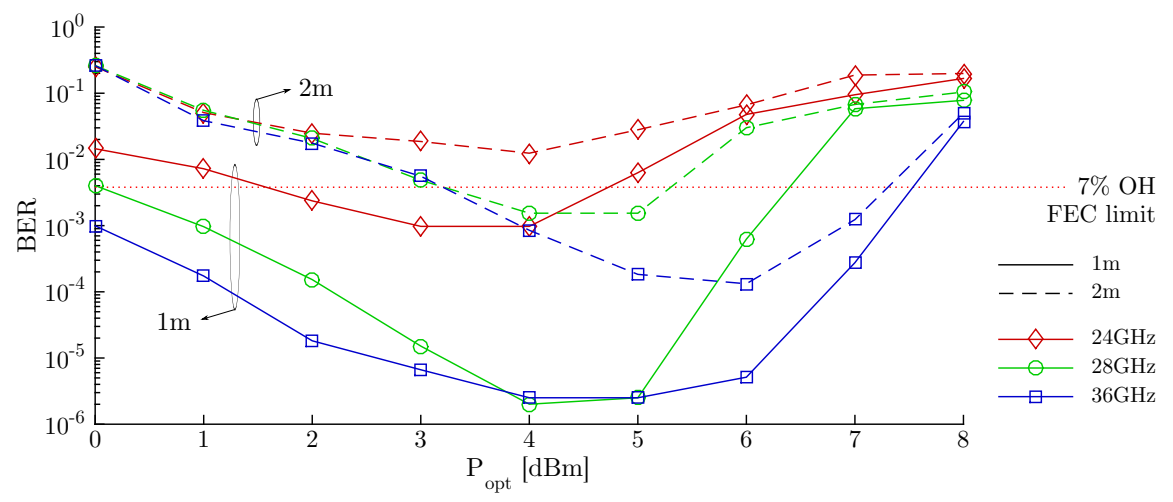

Fig. 3. Evolution of BER vs $P_{\text {opt }}$ for a $4 \mathrm{Gbit} / \mathrm{s}$ duobinary signal on different RF carrier frequencies after transmission over $12.5 \mathrm{~km} \mathrm{SMF}$ and wireless distances of $1 \mathrm{~m}$ and $2 \mathrm{~m}$

to degrade due to the PD becoming saturated.

While the performance with Ka-band carriers at $28 \mathrm{GHz}$ and $36 \mathrm{GHz}$ is very similar-with slight improvements from higher antenna gain and directivity for the higher frequency carrier-the performance of the K-band carrier at $24 \mathrm{GHz}$ is severely degraded by being at the very edge of the antenna transmission region. Consequently while at $1 \mathrm{~m}$ wireless distance and optimum incident power the performance of all carriers remains below the $3.8 \cdot 10^{-3}$ BER limit of a $7 \%$ overhead $(\mathrm{OH})$ commercial forward error correction (FEC), at $2 \mathrm{~m}$ this is only case for the Ka-band carriers. The limitation of transmission distance is due to low received RF powers and the consequent impact of quantization noise; an extension of transmission distance is expected to be possible through introducing additional RF amplification.

\section{Conclusions}

In this work we demonstrated transmission of a $4 \mathrm{Gbit} / \mathrm{s}$ duobinary signal over a Ka-band hybrid photonic-wireless link employing a set of RF carriers in the frequency bands allocated for possible use in mobile communications. Transmission with BER below the limit of a commercial FEC with $7 \%$ overhead is achieved over $12.5 \mathrm{~km} \mathrm{SMF}$ and $2 \mathrm{~m}$ wireless distance.

\section{Acknowledgments}

This work was partly funded by the DFF FTP mmW-SPRAWL, EC IPHOBAC-NG and Villum Kann Rasmusen SEES projects.

\section{References}

[1] H. Zhao, R. Mayzus, S. Sun, M. Samimi, J. K. Schulz, Y. Azar, K. Wang, G. N. Wong, F. Gutierrez, and T. S. Rappaport, " $28 \mathrm{GHz}$ millimeter wave cellular communication measurements for reflection and penetration loss in and around buildings in new york city," in Proc. ICC 2013 (IEEE, Budapest, 2013), pp. 5163-5167.

[2] T. Hirasawa, K. Minoguchi, M. Oishi, S. Akiba, J. Hirokawa, and M. Ando, "Amplitude modulated digital signal transmission in RoF system for MMW-RF antenna beam steering," in Proc. OECC 2015 (Shanghai, 2015).

[3] S. Rommel, A. Galvis Quintero, L. C. P. Cavalcante, J. J. Vegas Olmos, and I. Tafur Monroy, "Channel characterization for high-speed W-band wireless communication links," in Proc. OECC 2015 (Shanghai, 2015).

[4] A. Lender, "Correlative digital communication techniques," IEEE Trans. Commun. Technol. 12, pp. 128-135 (1964).

[5] R. D. Howson, "An analysis of the capabilities of polybinary data transmission," IEEE Trans. Commun. Technol. 13, p. 312-319 (1965).

[6] A. Sekey, “An analysis of the duobinary technique," IEEE Trans. Commun. Technol. 14, pp. 126-130 (1966).

[7] J. J. Vegas Olmos, L. F. Suhr, B. Li, and I. Tafur Monroy, "Five-level polybinary signaling for 10Gbps data transmission systems," Opt. Express 21, pp. 20417-20422 (2013). 